Article

\title{
Beyond Apprenticeship: Knowledge Brokers and Sustainability of Apprentice-Based Clusters
}

\author{
Huasheng Zhu ${ }^{1}$, Kelly Wanjing Chen ${ }^{2}$ and Juncheng Dai ${ }^{3, *}$ \\ 1 School of Geography, Beijing Normal University, 19 Xinjiekouwai Street, Beijing 100875, China; \\ zhuhs@bnu.edu.cn \\ 2 Department of Geography, University of Wisconsin-Madison, 550 North Park Street, Madison, WI 53706, \\ USA; wchen275@wisc.edu \\ 3 School of Culture and Communication \& Cultural Economics Research Institute, \\ Central University of Finance and Economics, 39 South College Road, Beijing 100081, China \\ * Correspondence: daijuncheng@cufe.edu.cn; Tel.: +86-10-6226-8292
}

Academic Editors: Hongbo Liu, Sizhong Sun and Iain Gordon Received: 17 September 2016; Accepted: 3 December 2016; Published: 7 December 2016

\begin{abstract}
Knowledge learning and diffusion have long been discussed in the literature on the dynamics of industrial clusters, but recent literature provides little evidence for how different actors serve as knowledge brokers in the upgrading process of apprentice-based clusters, and does not dynamically consider how to preserve the sustainability of these clusters. This paper uses empirical evidence from an antique furniture manufacturing cluster in Xianyou, Fujian Province, in southeastern China, to examine the growth trajectory of the knowledge learning system of an antique furniture manufacturing cluster. It appears that the apprentice-based learning system is crucial during early stages of the cluster evolution, but later becomes complemented and relatively substituted by the role of both local governments and focal outsiders. This finding addresses the context of economic transformation and provides empirical insights into knowledge acquisition in apprentice-based clusters to question the rationality based on European and North American cases, and to provide a broader perspective for policy makers to trigger and sustain the development of apprentice-based clusters.
\end{abstract}

Keywords: local learning; knowledge brokers; apprentice-based clusters; antique furniture manufacturing; China

\section{Introduction}

The emphasis on studying the knowledge management of industrial clusters has gradually shifted to cluster knowledge transference and knowledge channels in knowledge networks [1]. As a channel for acquiring and improving crafts and skills, apprenticeship systems have had much significance to local, traditional, craft-based clusters. In some of the traditional industries of developed countries, apprenticeship training has experienced significant decline over the last three decades [2], however, it is still promoted due to its orientation on firm-specific skills and its lower, staggered investment profile [3]. Moreover, in the newly emerging cultural creative clusters in developing countries (such as Dafen Oil Painting Village in Shenzhen, China [4]), apprenticeship is also a fundamental means of local knowledge transfer within the cluster. This is the so-called apprentice-based cluster ("ABC" in abbreviation), characterized by high levels of non-market coordination and regulated through consensus between employers, trade unions and government [5]. Many traditional ABCs in these countries have relied on family-owned workshops or small and medium-sized enterprises (SMEs), and knowledge has mainly been shared between family members and passed down over many generations. 
However, many of the theories on the knowledge dynamics associated with creative industry are based upon high-tech or service sectors like the design and film industries [6,7]. This has resulted in a relative dearth of understanding on the learning system within sectors that fall into the category of "creative industry", but are qualitatively different from those sectors that are often found in the metropolitan areas of an advanced economy. Biased empirical grounding could further skew theorization forming "urban bias" [7]. Both issues have been noticed and criticized in some recent works on craft-based creative industries, or on creative economies in rural or other less advanced settings [8,9]. This paper examines an antique furniture manufacturing cluster in rural China, which could be projected as a continuation of such scholarly tendencies.

In addition, much attention has been paid to knowledge learning systems mainly derived from high-tech and creative clusters in developed countries [1], rather than craft industries in the ABCs. Asian experiences from traditional industrial clusters (ABCs in particular) have made little contribution to this research. It is currently considered that contexts are the outcome of cluster history, and that they in turn shape the potential trajectory of a cluster [10]. Therefore, this paper focuses on ABCs within the context of Chinese economic transformation, a subject worthy of great consideration, but which has been generally overlooked in the related research [11].

Since the end of the Cold War, together with other emerging economies such as India and Brazil, China has strengthened its position on the world stage as the "factory of the world" due to its economic growth and institutional transformation. However, in recent times China has been facing increasing labor costs and competition from other developing countries [12,13], and both foreign-firm-dominating clusters and domestic-firm-driving cities have been attempting to make economic structural adjustments and industrial upgrades, in order to construct a "creative society" and sustain regional competitive advantages [14]. In short, China is at a critical stage of switching from a pattern of a high growth rate but low growth quality, to one of growth with high quality. In such a transition, it is important to document not only the changes within traditional sectors, but also to those within the new economy sectors [15]. It is hoped that the new economy sectors will serve as a new engine for China's further growth. However, it is also very true that ABCs have been significantly under-represented in the literature surrounding "new economies". Lacking other new channels of knowledge creation and transmission, $\mathrm{ABC}$ s have encountered serious challenges to the inherence and innovation of local traditional crafts and skills, and have declined in local sustainability [16]. The greatest challenge faced by $\mathrm{ABC}$ s is the closure of kinship knowledge learning systems. To open up this closed knowledge system, it is urgent for $\mathrm{ABC}$ s to update their knowledge learning systems by means of a knowledge broker capable of building new knowledge channels and of reconstructing the regional advantages of $\mathrm{ABCs}$.

Above all, this paper would contribute to the debate surrounding China's current economic transition from "made in China" to "create in China" from the standpoint of knowledge learning system changes on ABCs. It thus addresses the following research questions: (1) How to break the relatively closed knowledge system of an $A B C$ through knowledge brokers, while still preserving the sustainability of a traditional $\mathrm{ABC}$ within the context of economic transformation in emerging economies like China? (2) How can knowledge brokers play a dynamic role in the cluster learning process? In the next section, review the literature on knowledge learning systems, especially knowledge brokers. Section 3 introduces the research method and a case study, the antique furniture manufacturing (AFM) cluster in Xianyou County, Fujian Province, China. Section 4 describes the evolution processes of the knowledge learning system in the AFM cluster. Section 5 offers theoretical discussions and policy implications.

\section{Literature Review}

In the current knowledge-based economy, traditional production factors are currently no longer enough to sustain the competitive advantage of an industrial cluster (IC); knowledge is being called on to play a key role [17]. Over the past 20 years, four key approaches to knowledge systems have 
been discussed: (1) the knowledge-based approach; (2) the Science-Technology-Innovation (STI) and Doing-Using-Interacting (DUI) modes of innovation; (3) the regional innovation systems (RIS) concept; and (4) the local buzz and global pipelines argument [1]. However, the core weaknesses of these approaches are that they are mainly derived from innovation and creative clusters in Europe and North America, which cannot be transplanted to developing economies. In addition, empirical studies on the connections between actors focus to a very large extent on standardized indicators of innovation activities, such as patent data, R\&D employment or expenditures et al.; whereas within the context of $\mathrm{ABCs}$, these indicators are not easily valued, and the importance of the individual, as well their personal learning networks, tends to be neglected. Since many ABCs are transforming into innovational or creative clusters, how their knowledge learning system changes during the process needs reconsideration.

\subsection{Learning System of $A B C s$}

Unlike the common utilization of mass production and the heavy reliance on machine tools in some manufacturing sectors, industries within ABCs mainly need delicate handicraft skills [9]. The apprentice system is still pervasive and widespread in developing countries. It is basically a small scale, cottage sector, to a great extent passed from generation to generation, and has solved the socio-economic problems of both the rural and the county economy at large [18]. In the typical case of Houli's Saxophone Cluster in Taiwan, the knowledge and skills of saxophone production have mainly been passed down between family members, relatives and close friends. Kinship can be seen as the main knowledge channel for ABCs.

A line of literature also addresses the function of kinship in maintaining links to the place of origin. In a case study of the diamond-cutting industry in India, Henn highlights that global pipelines established by family businesses are selective, and family networks of transnational entrepreneurs may form global pipelines [19]. Nelly and Bontis reported that strong family ties are needed to transmit idiosyncratic knowledge, and they found that changes in kinship and interactions between individuals, the family, and business networks affect knowledge transfer and the nature and flow of shared information [20]. Mustafa and Chen classified family members into four categories according to social distance and found evidence of knowledge support from immediate, extended, and distant family members, which showed that knowledge is transferable through kinship and family ties [21]. These findings indicate that knowledge can flow informally through space driven by family ties. The family tie-based relationships are long lasting, require frequent contact to be activated, and provide capital, labor, emotional, and knowledge-based support to the ABCs.

However, it is argued that localized learning is not enough to sustain the longstanding innovation capability of a place. Kinship limits knowledge sharing among family members, as shown by early work in the high-tech industry in Silicon Valley, the film industry in Los Angeles, and the Swedish biotechnology and Irish software industries [22,23]. The close-knit kinship and apprenticeship-based network retard the knowledge spillover to some extent, and the apprentice-based clusters have become lethargic in adapting to changing environments, and locked into increasingly less dynamic development paths [4]. To avoid this lock-in danger, it is vital to discuss which actors could serve as a pipeline for knowledge flow between a place and the outside world, and also help the place to avoid being locked in the negative effects of over-dependency on kinship-based learning in ABCs. As a result, more and more researchers have shed light on the importance of knowledge brokers.

\subsection{Main Body and Functions of Knowledge Brokers}

Knowledge brokers can be understood as persons or organizations that facilitate the creation, sharing, and use of knowledge [24]. Nowadays, the concept of knowledge brokers seems to be growing in importance in a variety of areas [25], such as "boundary spanning knowledge broker' for engineers [26], and academic brokers in the scientific fields" [27]. Some studies even argue that "knowledge brokering is a fundamental characteristic of postmodern professionals" [28]. Meyer made 
a brief introduction that stated that the notion of knowledge broker, the place of brokering, theorization regarding the practice of brokering, and the broker's position are the most frequently asked questions about knowledge brokers in the literature [29]. In view of the two core questions to be studied, this paper focuses on the main body and function of knowledge brokers.

Scholars argue that knowledge brokers might be individuals [30-33] or organizations [34-37]. In practical terms, universities, $R \& D$ facilities, financial agencies and even whole countries are said to act as knowledge brokers [27]. These agencies might seem to have little influence on ABCs, but it is important to not neglect that knowledge brokers tend to be invisible and take place "back stage" [38] (p. 361). Therefore, it is necessary to reconsider the role of local governments in ABCs, which can also take on the responsibility of knowledge transfer as a knowledge broker. Commonly, governments develop the culture and infrastructure to support academic entrepreneurship and the commercialization of technology by establishing public research institutions [39]. Some also argue that governments can promote the development of intermediate or networking organizations [40] and support the collaborative system by establishing social ties and trust by promoting interaction and engagement [41]. These ties could bring about an improvement in the knowledge capacity of local firms within the cluster. Moreover, temporary clusters, such as trade fairs, professional exhibitions, and conferences, have been proved to be effective channels for external learning [42]. However, the role of local government, especially in developing countries, has been neglected. Some researchers point out that governments have limited capacity to establish successful industrial policies and argue that the success of governments at facilitating clusters is questionable, as shown by the case of Houli [9].

Classic perspectives on industrial clusters views knowledge as circulating spontaneously [43], and highlight the presence of focal firms within industrial clusters playing a leading role in the transmission of technology and knowledge $[44,45]$. The presence of focal firms in a cluster substantially increases knowledge spillover at the local level, both by creating technologically-advanced new knowledge, and by favoring the absorption and dissemination of external knowledge into the cluster [46]. In addition, focal firms perform searching and translating functions to acquire external knowledge, which they convey to neighboring firms facing knowledge-related disadvantages due to a lack of external connections, and thus link the region with the outside world [28]. Here, we should not neglect one type of focal firm, namely the focal outsider, which can refer to (1) focal firms from outside the cluster location; or (2) local focal firms that are at the forefront of their field but act as a "layman" for a new sector they enter later. The latter is referred to here. The focal outsider does not understand the industry's knowledge and skills, and is seemingly unable to effectively assume the role of gatekeeper. In turn, they will be more willing to pool together the different forms of knowledge, transforming them into a new knowledge, and virtually assuming the role of knowledge gatekeeper. It is worthy to study whether a focal outsider is a spoiler or an integrator in an industrial cluster.

Most studies recognize the key function of knowledge brokers as bridging organizations or gatekeepers that mediate the flow of knowledge and information between two unconnected actors [47]. Some identified functions even transcend the more typical mediating functions, including various combinations of functions and roles [48]. Hargadon and Sutton suggest two functions related to their network position: transferring and combining knowledge [49]. Other authors focus more on gatekeepers and identify three functions: searching external knowledge, transcoding it, and sharing it internally [50]. Oldham and McLean expanded the knowledge broker into three roles, namely knowledge managers, linkage agents, and capacity builders [51]. Boari and Riboldazzi developed the brokerage typology, including the coordinator (participants and the broker are from the same community), representative (one participant deliberates over exchanges with "outsiders"), the gatekeeper (the broker acts like a link between outsiders and members), the liaison (the broker is an outsider who links communities together during exchange and deliberation) and the cosmopolitan (a member of a community acts like a broker between members of other communities) [52]. Brokers can play these roles in different functions, which is not a simple functional classification. Therefore, 
it is necessary to explore when and how knowledge brokers play a dynamic role in the upgrading process of an industrial cluster.

\section{Empirical Context and Methodology}

\subsection{Study Area}

This paper uses empirical evidence from an AFM cluster in Xianyou County, Fujian Province, in southeastern coastal China (Figure 1), to test how different local knowledge brokers are interwoven with cluster development. We use Xianyou as a typical case because it is famous for its traditional crafts, has a dominant share in the domestic market, and represents an endogenous cluster in rural China. Being short of natural resources, Xianyou County used to depend heavily on agriculture. It has made great progress in local development since the 1980s with its burgeoning AFM cluster. Rapid development has taken place in the cluster since the mid-2000s, and the annual production value has climbed from 0.5 billion RMB in 2006 to 30 billion RMB in 2013, a 60-fold increase (Figure 2). The value added by this AFM accounted for 40 percent of the GDP in Xianyou, and its furniture manufacturing represented 60 percent of the domestic market share in 2013. In 2015, Xianyou has more than 2600 AFM firms with 120,000 employees, which mainly distribute in the Duwei, Daji, Bangtou villages (Figure 1). Xianyou was named "Chinese Classical Furniture Capital" and is one of the three largest rosewood classical furniture manufacturing bases in China (the other two are Dacheng in Hebei Province and Dayong in Guangdong Province).

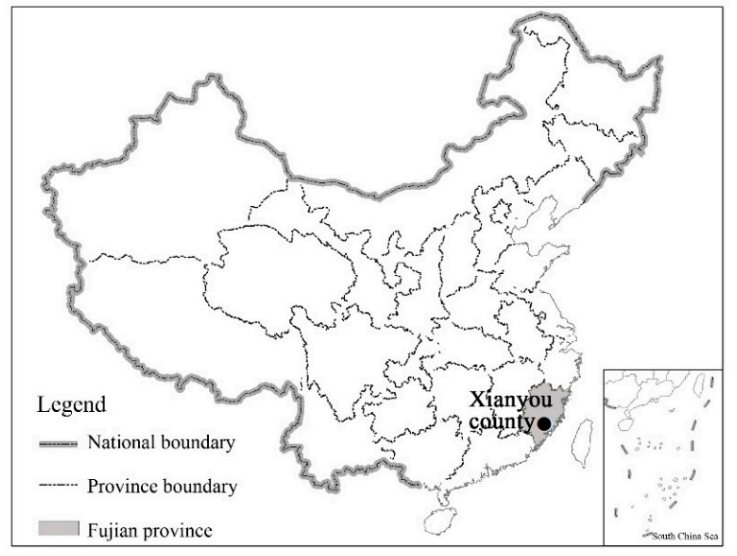

(a)

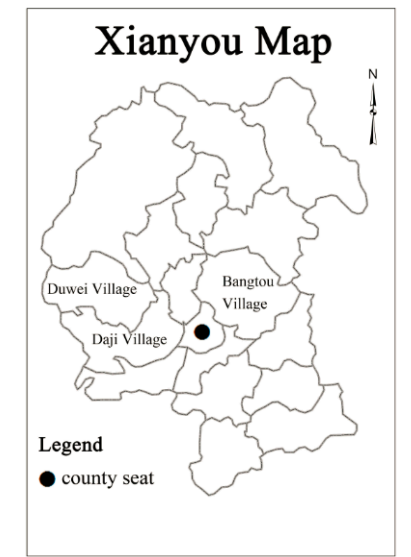

(b)

Figure 1. Geographical location of Xianyou County, China. (a) Location of Xianyou in China; (b) Main towns in Xianyou AFM cluster.

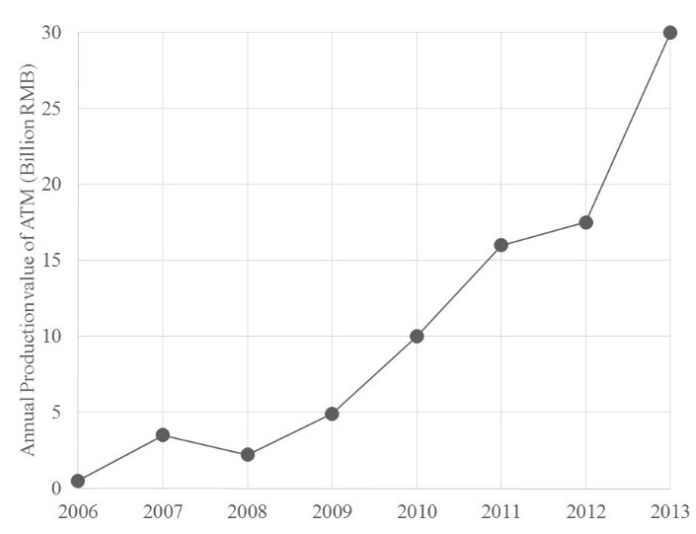

Figure 2. Annual production of the Xianyou ATM industry, 2006-2013 (units in billions of RMB). Source: Xianyou County Statistics Division (2007-2014). 


\subsection{Methodology}

One of the main authors of this article comes from Xianyou County and has witnessed the transitions of the cluster over time, and the use of the local dialect during field research was helpful when contacting local firms and communicating with residents. The case study included a total of three rounds. We conducted an exploratory interview at the beginning, and derived this paper's focus from the responses of these initial interviewees. Once a clear research direction was identified, we conducted two rounds of follow up interviews to unpack the specificity of the two types of knowledge brokers: the government and outside firms. The main issues covered in all three rounds of interviews were the various mechanisms through which knowledge is transferred and innovation is provoked.

The first round of investigation was initiated in 2011. During one month of extensive fieldwork, 6 technical experts, 4 AFM firm owners, and 2 local government officials were interviewed to collect information about the history and status of the local AFM industry, and the learning activities within and beyond the cluster. The interviewees were identified by personal recommendation, and they were highly respected in local professional fields. Each interview lasted a minimum of $45 \mathrm{~min}$.

In 2012, 44 firms of various sizes were visited. Large and medium sized firms with a staff of more than 100 people were selected and then contacted among the name list made by the authors according to the initial interviews, and eventually nine firms accepted the invitation for an interview. Through random sampling on the main streets of Xianyou County, the authors got the permission of 13 small firms with a staff of less than 100, and 22 family-owned factories with a staff of less than 20, to participate in a semi-structured interview. The basic information of these 44 interviewed firms is listed in Table 1. This fieldwork aims to gather more detailed information on internal learning within a firm, knowledge brokers within the cluster and their roles in changes in knowledge transfer among local firms and that between local and trans-local sources. This information was obtained through conversations of at least one hour with each owner or manager of the 44 firms. Key points from all the interviews were recorded for repeated analysis. Other sources of data were collected including local government working reports, local newspapers, and television interview programs.

Table 1. Information from interviewed AFM firms in Xianyou County.

\begin{tabular}{|c|c|c|c|c|c|}
\hline Staff Size & No. & Location & No. & Registered Years & No. \\
\hline$\geq 301$ & 3 & Jiaowei & 6 & $\geq 10$ & 5 \\
\hline $101-300$ & 6 & Duwei & 7 & $5-10$ & 10 \\
\hline $21-100$ & 13 & Daji & 10 & $3-5$ & 19 \\
\hline \multirow[t]{2}{*}{$\leq 20$} & 22 & Shima & 4 & $<3$ & 10 \\
\hline & & Bangtou & 17 & & \\
\hline Sales Modes & No. & Targeted Market & No. & Production Mode & No. \\
\hline Depending on local other AFM firms & 10 & All over the country & 21 & Transitional production & 16 \\
\hline others & 2 & & & & \\
\hline
\end{tabular}

The third round of the survey was conducted in February 2014. To assess changes in production value, apprentice system and knowledge channels in the cluster, we made an in-depth interview with 15 representative firms, approximately $1 / 3$ of them being from the 44 firms interviewed in 2012. All the interviewed firms are coded with their title's initials.

\subsection{Knowledge of the AFM Cluster}

The AFM cluster in Xianyou is a prime case for the investigation of knowledge system upgrading. With its traditional hands-on production, the AFM is a typical apprentice-based industry. Most local AFM-related knowledge has been passed down for generations through learning-by-doing and learning-by-monitoring among craftsmen. According to the survey, besides a large investment in high-priced rosewood, the two most crucial sets of knowledge that determined entrepreneurial potential and a firm's performance in the initial stage of the cluster were manufacturing know-how 
(about material identifying, carving, and assembling) and market status. The local manufacturing chain was separated into six processes; the skills or knowledge contained in each process are listed in Table 2.

Table 2. Manufacturing processes and skill requirement of antique furniture in Xianyou.

\begin{tabular}{llll}
\hline Process & Skills and Knowledge & $\begin{array}{l}\text { Skill Structure } \\
\text { of Apprentices }\end{array}$ & Learning Time \\
\hline 1. Raw material preparation & $\begin{array}{l}\text { of selecting raw materials (including } \\
\text { choice of wood) }\end{array}$ & Mostly MA, some SMA & At least two or three years \\
\hline 2. Wood repair & $\begin{array}{l}\text { of cracking off, repairing defective/cracked } \\
\text { timber by filling with pieces cut to fit the } \\
\text { size, color, and pattern of the defect }\end{array}$ & Mostly MA & At least two or three years \\
\hline 3. Carving & $\begin{array}{l}\text { of cutting raw materials into the rough } \\
\text { shape of each component }\end{array}$ & MA only & At least three years \\
\hline 4. Mechanical processing & of extending the pattern & Mostly FA & Almost half year \\
\hline 5. Burnishing and polishing & of burnishing and polishing the final piece & Mostly FA & Several weeks \\
\hline 6. Installing & of combining different parts into one piece & $\begin{array}{l}\text { Mostly ML, some SMA } \\
\text { and FA }\end{array}$ & Half a year \\
\hline
\end{tabular}

Source: Structured questionnaire in 2012. MA (mature apprentices), skilled apprentices who can work independently on all steps in the process; SMA (semi-mature apprentices), skilled apprentices who can work independently on part of the process; FA (fresh apprentices), apprentices who work on the simplest processes under the guidance of others.

Among the six processes mentioned above, raw material preparation and carving are considered the most knowledge-intensive. The former requires knowledge about redwood structure and patterns and cutting skills to make the best use of raw materials. Because of the high price of redwood resources, even small mistakes can cause huge losses for the workshops. Carving skill and artistic talent are needed to shape raw materials into specific components according to the product design. The last three processes in Table 2 require relatively little know-how and creativity; novice workers can perform them independently after several weeks' training.

In the hand-made stage, for an apprentice to learn all the processes usually requires a long time, at least more than five years. Whereas the market demand is relatively stable, with handmade furniture preferred by the rich, the raw materials are always expensive, giving apprentices fewer chances for practical operations and extend the time required for learning-by-doing. However, with recent developments in modern furniture technology, the market-orientation has also changed from high-end to common consumers who do not value handmade skills as much, and as a result, the antique furniture skills require less time to learn. It is during this process-of ABCs facing a transition brought on by technological advancements- that the role of knowledge brokers began to be emphasized.

\section{Development Path of Knowledge Learning in the AFM Clusters in Xianyou}

\subsection{Phase I: Indigenous Creation and Kinship-Based Learning Systems}

\subsubsection{Kinship as a Facilitating Channel for Initial Knowledge Learning}

The idea that the dynamics and complexity of kinship bonds affect the learning processes of industrial clusters have addressed in several studies [12]. The establishment of family-owned AFM firms and their spinoffs contributed to the origin of the cluster. Local firms and individuals had frequent face-to-face communication, and an "industrial atmosphere" prevailed. Their spinoffs contributed to the origins of the cluster. All the spinoffs basically inherit their mother firm's production technology and operation routines, and their kinship and then apprentice relationship informally construct a kind of local knowledge community, comprised of local firms and individuals. However, this alone did not facilitate the spillover of valuable knowledge. Our fieldwork revealed that in the initial stage, the diffusion of core know-how and useful information in furniture manufacture was limited to kinship networks, which acted as a bridge combining neighboring AFM firms that had related 
founders, and that these networks also acted as a wall that separated firms and limited professional knowledge sharing. Generally, a workshop and its spinoffs constitute a dependent "kingdom of skills", with different workshops rarely exchanging information and knowledge.

Traditionally, close kinship with owners of AFM firms or experienced craftsmen was a prerequisite for an individual beginning a career in the AFM industry. Even within firms, workers do not have equal opportunities to obtain knowledge. It is common for young craftsmen to work independently on mold carving, while older workers perform installation or detailing. On-site interviews revealed that the closer biological relationship a worker has with the owner, the more trust he can gain, and therefore the more opportunities he has to learn core skills. In YBF, an AFM firm with a typically traditional operation system in Bangtou Village, a 23-year-old craftsman, the owner's son, said, "You know, rosewood is very expensive so it must be cut correctly, which requires excellent skill. Either my father or I must be here every day to be in charge of raw material preparation. My father taught me the cutting skills one-on-one, and now I am quite good at this (process). No one else in the firm could do it properly". Meanwhile, other craftsmen interviewed from YBF complained that they cannot acquire the most highly paid skills, simply "because we have no (close) kinship with the owner or the experienced craftsmen".

As the core of a family-owned firm's competitiveness, crucial skills are often kept within the family. The craftsman-owner and other experienced craftsmen intentionally inhibit the acquisition of knowledge by new workers who are not biologically related, by subtle behaviors such as maintaining separate rooms for key processes to prevent observation, by assigning these workers easier steps, and by offering less useful advice. As the owner of SF mentioned in the interview of 2014, almost all of the entrepreneurs in Bangtou Village were born into aristocratic woodcarving families going back at least four or five generations.

Such kinship-based knowledge diffusion primarily occurs for two reasons. First, in agrarian communities with scarce natural resources, some individuals derive their income from special skills. Core AFM-related skills acquired over generations are valued as a family heritage, and the original creativity is protected by traditional transmission channels, i.e., inheritance. Teaching core knowledge to individuals outside of the family can lead to increased competition. Second, learning by doing within a family-owned firm is a traditional pathway of local skill training. Such in-house training can provide owners with an economic return in the form of training fees, as well as inexpensive or even free labor (young people that are unrelated to the industry owners must pay for their apprenticeship).

In addition, apprentices often perform extra household tasks and give gifts to owners on traditional Chinese holidays such as Spring Festival, Dragon Boat Festival, and Mid-autumn Day. As their skills increase, apprentices can get paid more; eventually, some leave to establish their own workshops if they have enough capital and customer resources. Therefore, owners generally prolong the learning process in order to gain a return on their investment in this informal in-house training. The importance of kinship in knowledge flow was emphasized in the knowledge creation stage and the familial network acts as a socialization tool that influences the intensity of engagement of individuals to the family [53].

\subsubsection{Limits in Apprentice-Based Learning System of the AFM Clusters}

Since local demand is limited in the initial stages, craft entrepreneurs build and rely heavily on trans-local connections with relatives who immigrated to other cities, to establish opportunities for new business. Therefore, among skilled craftsmen, only those with extensive external connections are likely to succeed in their AFM businesses. Preexisting long-distance networks with migrants of local origin provide a crucial channel for local industry to reach outside markets. These migrants purchase products and provide valuable feedback.

However, at the end of the formation stage, the Xianyou cluster experienced local lock-in and lacked communication with the outside. As one interviewee from BJJ mentioned, "People were satisfied by the profit made by firms of this size and did not want to further expand through continued investment and 
sustainable innovation. They were afraid of potential loss in competitiveness due to expansion to new markets. This idea was mainly the personal opinion of some experts".

This idea meant that firms were satisfied with the existing status and did not adapt to changing market demand. The growth of the cluster slowed, in large part because of this complacency, which remains today on the part of some firm owners. During the semi-structured interviews, several interviewees expressed concerns about expanding their firms to the "right size". Because the AFM industry is relatively uncommon, entrepreneurs could not borrow substantially from previous experience and were more susceptible to misinformation. When actors within the cluster cannot discern the quality of the information they receive, the co-location of firms resulted in frequent interpersonal interactions, but did not result in a positive local buzz effect [54]. This result was due to fact that all members had similar knowledge sets, while core knowledge or tacit skills were kept inside a firm as a secret. The chaotic pieces of information they exchanged everyday were mostly useless and the closed knowledge system regenerated.

\subsection{Phase II: Local Government as a Knowledge Broker Taking Place "Back Stage"}

Unlike the common role of Chinese government mentioned by Gao, including driving the economy, seeking to attract foreign capital, opening markets and so on [55], in this case, the Xianyou government has tried to act as a broker for innovation rather than as a policy maker. All of the in-depth interviewees agreed that the most influential act performed by local government was to push knowledge spillover from outside of the cluster.

\subsubsection{Intensifying the Linkage between the Locale and the External}

Since the mid-2000s, local government has initiated revitalization programs to stimulate further growth potential. In the Eleventh Five-year Plan (2006-2010) of Xianyou, the AFM there was first listed as a promising industry that would be given greater policy attention. Several departments were established in the county government to be in charge of the AFM industry and to provide public services. The Professional Committee of Furniture in the Ming and Qing Dynasty, established in September 2004 as a subdivision of the Chinese Folk Craftsman Association, took part in professional communications to connect Xianyou with other regions in China, working out local standards for classical antique furniture and facilitating the inheritance and development of local knowledge.

It has recently become popular for local industrial clusters to establish regional brands. Because regional brands are generally authorized by higher-level governments, local governments have an advantage over individuals or firms in terms of political resources or connections. The Xianyou County government has tried to connect to related national administrative departments to establish regional brands with a "state prefix". Xianyou was officially designated the "Capital of Chinese Classical Furniture" in 2006.

Meanwhile, local government has tried to increase the coherence of the cluster by constructing physical infrastructure. One street refers to a 10-kilometer-long street of exhibition halls; Four Corridors refers to four conglomerations of AFM firms along Xianbang, Laibang, Xiandu, and Sanjiao roads; Two Parks refers to Xianyou Arts and Crafts industrial park and Xianzuo Logistics Park; Five Plazas refers to the Chinese classical technology expo city, Xianyou international oil city, Xianyou stone arts culture city, Yonghong cultural city, and the root carving antique city. Although there is little evidence that this planned infrastructure will enhance knowledge spillover, it does increase the opportunity for face-to-face communication among local firms. Moreover, trade and cultural events in the industrial parks and plazas provide public platforms for professional communication and information collecting, combining local and trans-local learning. Local government has also emphasized craftsman-training programs. A department of woodcarving arts was established in a vocational school and has provided students with AFM-related skill training as well as internship opportunities with local firms. 


\subsubsection{Temporary Cluster and Trans-Local Learning}

The entrepreneurs interviewed agreed that the most influential event marking a new era for the AFM cluster in Xianyou was collective participation in a national annual furniture fair in Beijing in 2006. The fair was launched by local government after a year of preparation. This event is viewed as having promoted national awareness of the Xianyou AFM and as having increased business opportunities. A government official in charge of organizing local firms in the fair emphasized that "Xianyou was not historically known for antique furniture... Many people had no idea that antique replica furniture was made in Xianyou in the past. This had caused huge marketing challenges for our local firms. Hence, at that time the government planned to build a stage for the industry. At the 2006 furniture fair, Xianyou became an overnight sensation, and our firms got a lot of orders too. It was a big success". Moreover, with the establishment of "Xianyou" as a regional brand, large numbers of clients started to visit and investigate the cluster. The owner of BGX in Daji Village confirmed this in his interview in 2014, saying "... Sales were no longer a big deal after 2006, because a lot of customers came here who were attracted by the name of Xianyou. Regular customers also introduced more new customers. You could even hear people on the street talking about orders, a big deal, or new customers".

The 2006 fair also had a profound effect on cluster learning. The owner of SF AFM Company, recalled that "It was the first time for most of us (participants from Xianyou) to have face-to-face dialog with peers from other regions in China and even abroad. During the fair, we visited an AFM company chain store in Beijing. What most impressed us was the exquisite show room where all the furniture was tagged with the company brand, and the clearly marked prices were much higher than ours. We were all thinking then that we should make some changes. We could do this too-place our products in a nice room, sell the furniture with our own brand, and charge a better price. Why not?"

Since the late 2000s, local government has organized trade fairs and cultural events to further increase its power in the national and global industry (Table 3), and it has encouraged local firms to attend trade fairs in other regions. Professional trade fairs have increased commercial opportunities and helped local firms to establish relationships with non-local agencies, which has led to less dependence on emigrant relatives.

Table 3. Local government-initiated promotional since 2009.

\begin{tabular}{|c|c|c|c|c|}
\hline Activity & Year Established & Partner(s) & Purpose/Function & Participants \\
\hline $\begin{array}{l}\text { "Yiding Cup": live } \\
\text { creative Chinese } \\
\text { wood-carving } \\
\text { competition }\end{array}$ & 2009 , annual & $\begin{array}{l}\text { China Arts \& Crafts } \\
\text { Association, Fujian Arts } \\
\text { \& Crafts Association, } \\
\text { Council of Putian Arts \& } \\
\text { Crafts Plaza }\end{array}$ & $\begin{array}{l}\text { To promote innovative } \\
\text { techniques in the } \\
\text { wood-carving industry, } \\
\text { communication between } \\
\text { related industries, and } \\
\text { industrial construction. }\end{array}$ & $\begin{array}{l}\text { In the sixth year (2014), } \\
27 \text { skilled wood carvers from } \\
10 \text { provinces (including Taiwan, } \\
\text { Zhejiang, and Guangdong) } \\
\text { attended the competition }\end{array}$ \\
\hline $\begin{array}{l}\text { International Wood } \\
\text { Culture Festival }\end{array}$ & 2014 & $\begin{array}{l}\text { International Wood } \\
\text { Culture Society }\end{array}$ & $\begin{array}{l}\text { To set up an interactive } \\
\text { platform for research, } \\
\text { discussion, exhibition, } \\
\text { and communication about } \\
\text { wood culture. }\end{array}$ & $\begin{array}{l}\text { More than } 400 \text { professional } \\
\text { participants and } 100,000 \text { visitors } \\
\text { from more than } 70 \text { countries and } \\
\text { regions; more than } 5000 \text { pieces } \\
\text { of wooden artwork } \\
\text { were exhibited. }\end{array}$ \\
\hline
\end{tabular}

Sources: [56-58].

The term "temporary cluster" used here to describe trans-local learning on these occasions, where the buzz of tacit knowledge is believed to exist as well [59]. Relying on the temporary cluster organized by local government, high-quality trans-local communication with external clients and peers ensure that local firms can easily access technological and organizational knowledge. Interactions between firms coming from different places could engage in effective learning [60]. The temporary cluster 
intensified trans-local learning and linkages, further speeding up the process of local knowledge creation and diffusion. Knowledge deeply embedded in the traditional kinship-based network began to be freed up in this stage.

\subsection{Phase III: Focal Outsiders Revive the Knowledge System}

Since the mid-2000s, a group of new investors who had no AFM-related career experience (hereby defined as "focal outsider") but who noticed the increasing profitability of AFM have entered this industry. According to the Xianyou Publicity Office, new AFM firms comprised roughly $20 \%$ of the cluster in 2013 and have already contributed to the increase in local annual production. The focal outsiders made crucial changes to the learning system of the AFM in Xianyou.

\subsubsection{Kinship Based Learning System Broken by New Investors}

Unlike traditional AFM firms in Xianyou, the focal outsiders have a broad vision based on their business experience in other industries or regions. They pay more attention to knowledge creation at both ends of the value chain (product design and development) and to branding and marketing innovation, rather than to traditional manufacturing knowledge.

To decrease the risk of overdependence on a few skilled craftsmen, they tend to codify traditional knowledge and standardize some manufacturing processes. Consequently, the apprenticeship period through learning-by-doing has been shortened, and new workers can operate machinery independently after a short training period (even only within a couple of days or weeks). More females, especially married women, who previously had few opportunities to engage in AFM and get a job outside the home for their traditional status in the family life, can now obtain full or part-time jobs in these new firms.

With the entry of these outsiders, significant changes have occurred in the local labor market that has affected local learning dynamics. Kinship-based learning and family-owned businesses generated little mobility for local craftsmen and labor in the initial stage. However, new firms have attracted local craftsmen with higher wages, closer family connections, or the owners' high social status in the locale (for example, two interviewees were the village heads), and these firms have also hired experts and skilled workers from other regions to expand production capacity. Some investors have even co-established AFM firms with local craftsmen. Competition for craftsmen among peer firms has increased greatly, and the mobility of ordinary workers and especially of experienced craftsmen has increased quickly, which facilitates knowledge flow. Because of the increased mobility of the local labor market, neighboring firms can obtain valuable information from one another, and the local buzz has been amplified.

\subsubsection{Focal outsiders Play as Knowledge Brokers}

The AFM cluster in Xianyou has undergone another crucial transformation since the worldwide financial crisis of 2008. This transformation began with the emergence of LTH, a large, modern AFM corporation in Xianyou. Mr. Li, the founder, invested 500 million RMB to build a large factory $\left(10,000 \mathrm{~m}^{2}\right)$, introduce up-to-date machinery, and recruit 3000 employees. To existing local firms, the huge investment of LTH, without a related career background, was viewed as a reckless decision and destined to fail. "Almost everyone predicted at that time that LTH would be a big joke. Everyone was mocking the recklessness of the businessman because he had never worked in this industry. Some firm owners explained their worry that LTH might take away their market share, but more strongly believed that it would close down within a short time. The public viewed the LTH firm as the product of an impractical investment", one interviewee from XBMY said. However, LTH grew quickly in the next five years and has become a major taxpayer and the top AFM firm in Xianyou. Its annual production value exceeded 10 billion RMB in 2013, accounting for close to one-third of the total value of the cluster.

Success of LTH was partly attributed to its innovative business model in combination with mass-production business experience borrowed from other regions and local, small-volume customized 
production based on traditional crafts. The founder, a successful businessman in the oil and natural gas sector, had financial resources and an open mind. He realized both the great potential value of traditional hands-on skills and the weak innovative capacity in local family-owned business compared to large companies in other cities of China.

The company established two production systems, one based on traditional hands-on methods, and the other based on modern mechanization. Local craftsmen have been employed to make high-quality AF by hand, to support traditional culture and to improve commercial value. To improve the productivity of mid- and lower-level manufacturing, the company uses modern machinery. Local knowledge has been codified in the form of patents, machinery, and technological pamphlets. Labor demand has increased as LTH has expanded its production, and many workers have immigrated into the cluster.

As with Hargadon and Sutton's notion that knowledge brokers' function as agents of knowledge transferring and combining [25], LTH plays two such roles to assure the survival and development of the entire district. On the one hand, LTH built the trans-local knowledge transferring channel to enhance external learning-based linkages. LTH has emphasized trans-local learning and has organized a team to collect the latest industry-related information at trade fairs, governmental conferences, and visits to outside AFM firms. Moreover, to improve its design and technological capability, LTH has established cooperative relationships with research institutions and universities (such as Nanjing Forestry University). As a consequence, a 300-person design department was established, and a new product line that combines characteristics of both antique and modern furniture was launched successfully in 2011. This new product line represents more than half of the firm's annual production. By February 2014, the number of product patents had reached 2000.

On the other hand, LTH acts as a talent reservoir that combines different knowledge sources. In order to obtain adequate high-quality labor and avoid potential overdependence on a few experienced craftsmen, LTH established a system of collective learning to initiate communication and discussion, encourage integrity of skills sets and knowledge, and give experienced craftsmen incentive to cultivate potential talent. During the 2008 crisis, many family-owned AFMs went bankrupt, and some owners applied for positions in LTH. A director of craftsmen in LTH recalled, "The boss often invited all the experienced craftsmen (in the firm) to sit together to discuss manufacturing skills and to work out a plan for training new craftsmen. Although we (the craftsmen) had known each other well before because we lived in the same town, we had never discussed such things in detail. You can imagine, such face-to-face communication and brainstorming are very efficient ways to deal with practical problems... We (skilled craftsmen) are responsible for on-site training of new workers and we can get extra bonuses as skilled trainers. According to the company's rule, we put individuals with strong talent or motivation in a special group and offer them more guidance".

With the goal of improving its status in the Chinese AFM industry and promoting the cluster's awareness in China and abroad, LTH has maintained an open business strategy and acts as a knowledge broker. All of its factories are open to clients, local people, AF fans and visitors, and peer firms (local and from elsewhere), which facilitates spillover of the company's internal knowledge among the cluster. The company also helps to connect local entrepreneurs with AFM-related practitioners in other places by hosting professional workshops, forums, expert lectures, topic conferences, and other activities for the AF fan club. These opportunities for face-to-face communication enable local firms to make trans-local connections without leaving the cluster.

\subsubsection{Transformation of Traditional AFM Firms}

In-depth interviews with four other entrepreneurs (LHS, HJJ, JFX, XMG) provided information about recent technological innovations and concerns about LTH and also confirmed the existence of effective localized learning. Furthermore, inspired by LTH's success, a new round of investments took place in the cluster. SZGD, established in 2010, is a typical case. These so-called "LTH style" firms 
strive to follow the open learning model in combination with local knowledge sharing with external learning channels.

As more successful LTH-style firms emerge in the cluster, traditional firms feel increasing pressure and are encouraged to invest in trans-local marketing networks and knowledge creation to keep pace with changes in the industry. In the words of L3's owner, "My family has been in this business for five generations, but we have never encountered such a serious challenge as what happened recently in the cluster. We have to make some crucial changes with the vision to promote our family business to a higher level; otherwise we will one day lose out to the increasingly serious competition". A group of traditional firms including SF have begun to cooperate with external schools of arts and crafts for technological innovation, product development, and craftsmen training.

Looking more closely at the recent transitions in the cluster learning system, signs of interactions between local and trans-local learning are apparent. New institutions that allow opportunities for local actors to learn core furniture manufacturing knowledge were started by LTH or were derived from ideas generated by visiting non-local actors. New ideas from outside mediated through brokers triggered the transition in learning mechanisms. The formation of active localized learning in turn resulted in the emergence of more trans-local linkages. As a firm acquires information and knowledge from neighboring competitors, it builds trans-local linkages to increase its own competitiveness. Following LTH's model, other larger local actors began to invest in building knowledge links with research institutions from outside the cluster.

\section{Discussion and Conclusions}

Against the background of China's economic transformation, whether China can avoid the middle-income trap is probably one of the most important economic questions facing the world today [61]. The dilemma that apprentice-based clusters are facing could be seen as a miniature version of China's economy that is unable to compete with either more advanced scientific parks (because of lower efficiency) or less developed economies (because of higher costs). From a national level to ABCs at the local level, significant efforts needs to be made to foster their innovation capability in order to survive amidst serious competition.

Therefore, the contributions of this research are two-fold. First, this paper addresses the context of economic transformation and provides empirical insights into knowledge acquisition in apprentice-based clusters rather than innovative and creative clusters. ATM industries, through upgrading their industrial knowledge, could also become the engine which drives the economic development of regions with similar knowledge-intensive industrial clusters. Second, it adds to the debate regarding the key issue of how knowledge brokers emerge and evolve during the transformation process of $A B C s$. It finds $A B C$ should break out of their traditional kinship-based learning system through employing knowledge brokers. We analyzed the role of government as well as focal firms as brokers driving the processes of new knowledge creation and diffusion within the ABCs and found that various actors played different roles in each stage of development. In the beginning stages of an apprenticeship industrial cluster, the knowledge system is relatively closed and cannot adapt to changes in the market, because the knowledge is based on kinship or relative transmission. With the scale of industrial clusters continuing to expand, the government set up a channel for knowledge connection between local industrial clusters and the outside world through exhibition, conference, and other forms. In addition, some "focal outsiders" have tried to function as agents of knowledge transferring and combining, thus promoting the re-development of the apprenticeship industry cluster.

The case of the AFM cluster in Xianyou demonstrates how a knowledge system evolves in ABCs. It appears that the apprentice-based learning system is crucial during early stages of the cluster evolution. At the intra-cluster level, knowledge is mainly shared through kinship relationships, which can result in frequent interpersonal interactions, but lacks a positive local buzz because members have similar knowledge sets but core knowledge or skills are kept secret. Later, the apprentice learning system was complemented and relatively relegated by local government and focal firms. In particular, 
the focal outsiders without an AFM-related background, such as LTH, acted as knowledge brokers in the cluster, significantly changing the learning ecology and growth trajectory of the cluster.

To sustain the ABCs, it is generally thought that government policies need to be cluster-specific [62]. The policies should focus on promoting knowledge centers and links to the outside and provide infrastructure for knowledge transference. To design and implement cluster-specific policies, government should assume the role of a knowledge broker to strengthen its governmental institutional capabilities, especially in linking firms or individuals to other non-firm actors in clusters such as universities, government R\&D institutes, and so on, by means of temporary clusters.

Furthermore, the knowledge brokers' role played by leading "focal outsiders" should not be underestimated, as in the case examined here, in which they built a platform for trans-local innovation. Although these focal outsiders accumulate little specific knowledge concerning new industries, they can use their experience from other industries and exert influence on local knowledge learning by generating knowledge spillover beyond their former learning networks. In addition, they also stimulate the mobility of the local labor market, which contributes to increasing knowledge spillover in the locale.

While we demonstrate the positive influences of these focal outsiders, it does not mean we should overlook the negative impact LTH has had on the sustainability of apprentice-based clusters. When such focal firms hire experienced craftsmen with a higher wage, it also means other peer firms lose excellent employees. Will it further reduce the profitability of the local smaller firms? Will the cluster confront a decline or "hollowing out" upon the relocation of LTH? These are questions that still require further investigation and discussion.

Acknowledgments: This research is supported by the National Natural Science Foundation of China (project code: 41171098) \& (project code: 41501149); Fundamental Research Funds for the Central Universities (project code: 2014KJJCB03). We would like to thank two anonymous referees for their constructive comments on an earlier version of the paper.

Author Contributions: Juncheng Dai and Huasheng Zhu contributed to the conceptual framework of the paper. Kelly Wanjing Chen contributed to the fieldworks.

Conflicts of Interest: The authors declare no conflict of interest.

\section{References}

1. Grillitsch, M.; Trippl, M. Combining knowledge from different sources, channels and geographical scales. Eur. Plan. Stud. 2014, 22, 2305-2325. [CrossRef]

2. Toner, P. Survival and decline of the apprenticeship system in the Australian and UK construction industries. Br. J. Ind. Relat. 2008, 46, 431-438. [CrossRef]

3. Paul, R.; Howard, G.; Paul, L. Large employers and apprenticeship training in Britain. Br. J. Ind. Relat. 2007, 45, 127-153.

4. Li, S.M.; Cheng, H.H.; Wang, J. Making a cultural cluster in China: A study of dafen oil painting village, Shenzhen. Habitat Int. 2014, 41, 156-164. [CrossRef]

5. Vona, F.; Consoli, D. Innovation and skill dynamics: A life-cycle approach. Ind. Corp. Chang. 2015, 24, 1393-1415. [CrossRef]

6. Vang, J.; Chaminade, C. Cultural clusters, global-local linkages and Spillovers: Theoretical and empirical insights from an exploratory study of Toronto's film cluster. Ind. Innov. 2007, 14, 401-420. [CrossRef]

7. Harvey, D.C.; Hawkins, H.; Thomas, N.J. Thinking creative clusters beyond the city: People, places and networks. Geoforum 2012, 43, 529-939. [CrossRef]

8. McAuley, A.; Fillis, I. Careers and lifestyles of craft makers in the 21st century. Cult. Trends 2005, 14, 139-156. [CrossRef]

9. Paulsen, K.; Staggs, K. Constraint and reproduction in an amateur craft institution: The conservative logic of the county fair. Poetics 2005, 33, 134-155. [CrossRef]

10. Martin, R.; Sunley, P. Path dependence and regional economic evolution. J. Econ. Geogr. 2006, 6, $395-437$. [CrossRef] 
11. Fitjar, R.D.; Rodríguez-Pose, A. Networking, context and firm-level innovation: Cooperation through the regional filter in Norway. Geoforum 2015, 63, 25-35. [CrossRef]

12. Wang, J. Industrial districts in a transitional economy, the case of Datang sock and stocking industry in Zhejiang, China. In Proximity, Distance and Diversity, Issues on Economic Interaction and Local Development; Lagendijk, A., Oinas, P., Eds.; Ashgate: Burlington, VT, USA, 2005; pp. 47-69.

13. Wang, J.; Tong, X. Clustering in China, alternative pathways towards global-local linkages. In Technological Innovation in China; Gu, S., Ed.; Institute for New Technology: Maastricht, The Netherlands, 2002.

14. Li, W.W. How Creativity is Changing China; Bloomsbury Academic: London, UK, 2011.

15. Shen, Y.; Shen, M.; Chen, Q. Measurement of the new economy in China: Big data approach. China Econ. J. 2016, 9, 1-13. [CrossRef]

16. Yan, H.D.; Kuo, Y.C.; Chen, S.Y. Entrepreneurship and an apprentice-based cluster, the evolution of Houli's saxophone cluster in Taiwan. Glob. Econ. Rev. 2011, 40, 483-502. [CrossRef]

17. Sureephong, P.; Chakpitak, N.; Ouzrout, Y.; Bouras, A. An ontology-based knowledge management system for industry clusters. In Global Design to Gain a Competitive Edge; Yan, X.T., Eynard, B., Ion, W.J., Eds.; Springer: London, UK, 2008; pp. 333-342.

18. Mir, L.A.; Bhushan, S. An analysis of current scenario and contribution of Handicrafts in Indian economy. J. Econ. Sustain. Dev. 2014, 5, 75-78.

19. Henn, S. Transnational entrepreneurs, global pipelines and shifting production patterns, The example of the Palanpuris in the diamond sector. Geoforum 2012, 43, 497-506. [CrossRef]

20. Nelly Trevinyo-Rodríguez, R.; Bontis, N. Family ties and emotions, a missing piece in the knowledge transfer puzzle. J. Small Bus. Enterp. Dev. 2010, 17, 418-436. [CrossRef]

21. Mustafa, M.; Chen, S. The strength of family networks in transnational immigrant entrepreneurship. Int. Bus. Rev. 2010, 52, 97-106. [CrossRef]

22. Bagwell, S. Transnational family networks and ethnic minority business development, the case of Vietnamese nail shops in the UK. Int. J. Entrepr. Behav. Res. 2008, 14, 377-394. [CrossRef]

23. Sternberg, R.; Muller, C. Return migration in regional innovation systems. Asian J. Technol. Innov. 2005, 13, 71-96. [CrossRef]

24. Sverrisson, A. Translation networks, knowledge brokers and novelty construction: Pragmatic environmentalism in Sweden. Acta Sociol. 2011, 44, 313-327. [CrossRef]

25. Bielak, A.T.; Campbell, A.; Pope, S.; Schaefer, K.; Shaxson, L. From science communication to knowledge brokering: The shift from "science push" to "policy pull". In Communicating Science in Social Contexts: New Models, New Practices; Cheng, D., Claessens, M., Gascoigne, T., Metcalfe, J., Schiele, B., Shi, S., Eds.; Springer: Amsterdam, The Netherland, 2008; pp. 201-226.

26. Johri, A. Boundary spanning knowledge broker: An emerging role in global engineering firms. In Proceedings of the 38th ASEE/IEEE Frontiers in Education Conference, Saratoga Springs, NY, USA, 22-25 October 2008.

27. Kissling-Naf, I. From a learned society to a 21st-century broker: The Swiss Academy of Sciences as a partner in the dialogue with society. Int. J. Technol. Manag. 2009, 46, 120-131.

28. Kakihara, M.; Sorensen, C. “Post-modern" professionals' work and mobile technology: New ways of working in IS. In Proceedings of the 25th Information Systems Research Seminar in Scandinavia, Copenhagen Business School, Frederiksberg, Denmark, 10-13 August 2002.

29. Meyer, M. The Rise of the Knowledge Broker. Sci. Commun. 2010, 32, 118-127. [CrossRef]

30. Malecki, E. Global knowledge and creativity: New challenges for firms and regions. Reg. Stud. 2010, 44, 1033-1052. [CrossRef]

31. Shi, W.; Markoczy, L.; Dess, G.G. The role of middle management in the strategy process: Group affiliation, structural holes, and terzius jungens. J. Manag. 2009, 35, 1453-1480.

32. Uzzi, B.; Spiro, J. Collaboration and creativity: The small world problem. Am. J. Sociol. 2005, 111, 447-504. [CrossRef]

33. Watts, D.J. Network dynamics and the small-world phenomenon. Am. J. Sociol. 1999, 105, 493-527. [CrossRef]

34. Wink, R. Gatekeepers and proximity in science-driven sectors in Europe and Asia: The case of human embryonic stem cell research. Reg. Stud. 2008, 42, 777-791. [CrossRef]

35. Graf, H. Gatekeepers in regional networks of innovation. Camb. J. Econ. 2011, 35, 173-198. [CrossRef] 
36. Hargadon, A.B. Firms as knowledge brokers: Lessons in pursuing continuous innovation. Calif. Manag. Rev. 1998, 40, 208-227. [CrossRef]

37. Lazaric, N.; Longhi, C.; Thomas, C. Gatekeepers of knowledge versus platforms of knowledge: From potential to realized absorptive capacity. Reg. Stud. 2008, 42, 837-852. [CrossRef]

38. Vogel, A.; Kaghan, W.N. Bureaucrats, brokers, and the entrepreneurial university. Organization 2001, 8, 358-364. [CrossRef]

39. Scott, A.J. Geography and Economy, Three Lectures; Oxford University Press: Oxford, UK, 2006.

40. Cooke, P. Regional innovation systems, clusters, and the knowledge economy. Ind. Corp. Chang. 2001, 10, 945-974. [CrossRef]

41. Kim, S.T.; Jeong, M.G. Discovering the genesis and role of an intermediate organization in an industrial cluster, focusing on connect of San Diego. Int. Rev. Public Adm. 2014, 19, 143-159. [CrossRef]

42. Amin, A. An institutionalist perspective on regional economic development. Int. J. Urban Reg. 1999, 23, 365-378. [CrossRef]

43. Brusco, S. The Emilian model: Productive decentralisation and social integration. Camb. J. Econ. 1982, 6, 167-184.

44. Agrawal, A.; Cockburn, I.M. University Research, Industrial RED and the Anchor Tenant Hypothesis; NBER Working Paper 9212; NBER: Cambridge, MA, USA, 2002.

45. Boari, C.; Lipparini, A. Networks within industrial districts: Organising knowledge creation and transfer by means of moderate hierarchies. J. Manag. Gov. 1999, 3, 339-360. [CrossRef]

46. Malipiero, A.; Munari, F.; Sobrero, M. Focal firms as technological gatekeepers within industrial districts: Knowledge creation and dissemination in the Italian packaging machinery industry. In Proceedings of the Communication to the DRUID Winter Conference, Rebild, Denmark, 27-29 January 2005.

47. Burt, R. Structural Holes; Harvard University Press: Cambridge, MA, USA, 1992.

48. Howells, J. Intermediation and the role of intermediaries in innovation. Res. Policy 2006, 35, 715-728. [CrossRef]

49. Hargadon, A.; Sutton, R.I. Technology brokering and innovation in a product development firm. Adm. Sci. Q. 1997, 42, 716-749. [CrossRef]

50. Morrison, A. Gatekeepers of knowledge within industrial districts: Who they are, how they interact. Reg. Stud. 2008, 42, 817-835. [CrossRef]

51. Oldham, G.; McLean, R. Approaches to Knowledge-Brokering. 1997. Available online: http://www.iisd. org/pdf/2001/networks_knowledge_brokering.pdf (accessed on 6 December 2016).

52. Boari, C.; Riboldazzi, F. How knowledge brokers emerge and evolve: The role of actors' behaviour. Res. Policy 2014, 43, 683-695. [CrossRef]

53. Passy, F.; Giugni, M. Social networks and individual perceptions, explaining differential participation in social movements. Sociol. Forum 2011, 16, 123-153. [CrossRef]

54. Bathelt, H.; Malmberg, A.; Maskell, P. Clusters and knowledge: Local buzz, global Pipelines and the process of knowledge creation. Prog. Hum. Geog. 2004, 28, 31-56. [CrossRef]

55. Gao, B. Neoliberal versus classical, Chinese and Japanese developmentalisms in comparison. Sociol. Res. 2006, 1, 116-141.

56. All Previous "Yiding Cup" Live Creative Chinese Wood-Carving Competition Winners. Available online: http://www.cngendiao.com/news/bencandy-htm-fid-49-id-2249.html (accessed on 7 December 2016). (In Chinese)

57. China Tour of "Xian Zuo". Available online: http://weibo.com/xzzgx?is_all=1 (accessed on 7 December 2016). (In Chinese)

58. 2014 World Wood Day and the First International Wood Culture Festival in Xianyou Opening. Available online: http://news.china.com.cn/shehui/2014-03/22/content_31871499.htm (accessed on 7 December 2016). (In Chinese)

59. Sotarauta, M.; Ramstedt-Sen, T.; Seppanen, S.; Kosonen, K. Local and Digital buzz, global or national pipelines: Patterns of knowledge sourcing in intelligent machinery and digital content services in Finland. Eur. Plan. Stud. 2011, 19, 1305-1330. [CrossRef]

60. Maskell, P. Towards a knowledge-based theory of the geographical cluster. Ind. Corp. Chang. 2001, 10, 921-943. [CrossRef] 
61. Huang, Y. Can China escape the middle-income trap? China Econ. J. 2016, 9, 1-17. [CrossRef]

62. Glasmeier, A.K. Territory-based regional development policy and planning in a learning economy the case of 'real service centers' in industrial districts. Eur. Urban Reg. Stud. 1999, 6, 73-84. [CrossRef]

(C) 2016 by the authors; licensee MDPI, Basel, Switzerland. This article is an open access article distributed under the terms and conditions of the Creative Commons Attribution (CC-BY) license (http://creativecommons.org/licenses/by/4.0/). 